
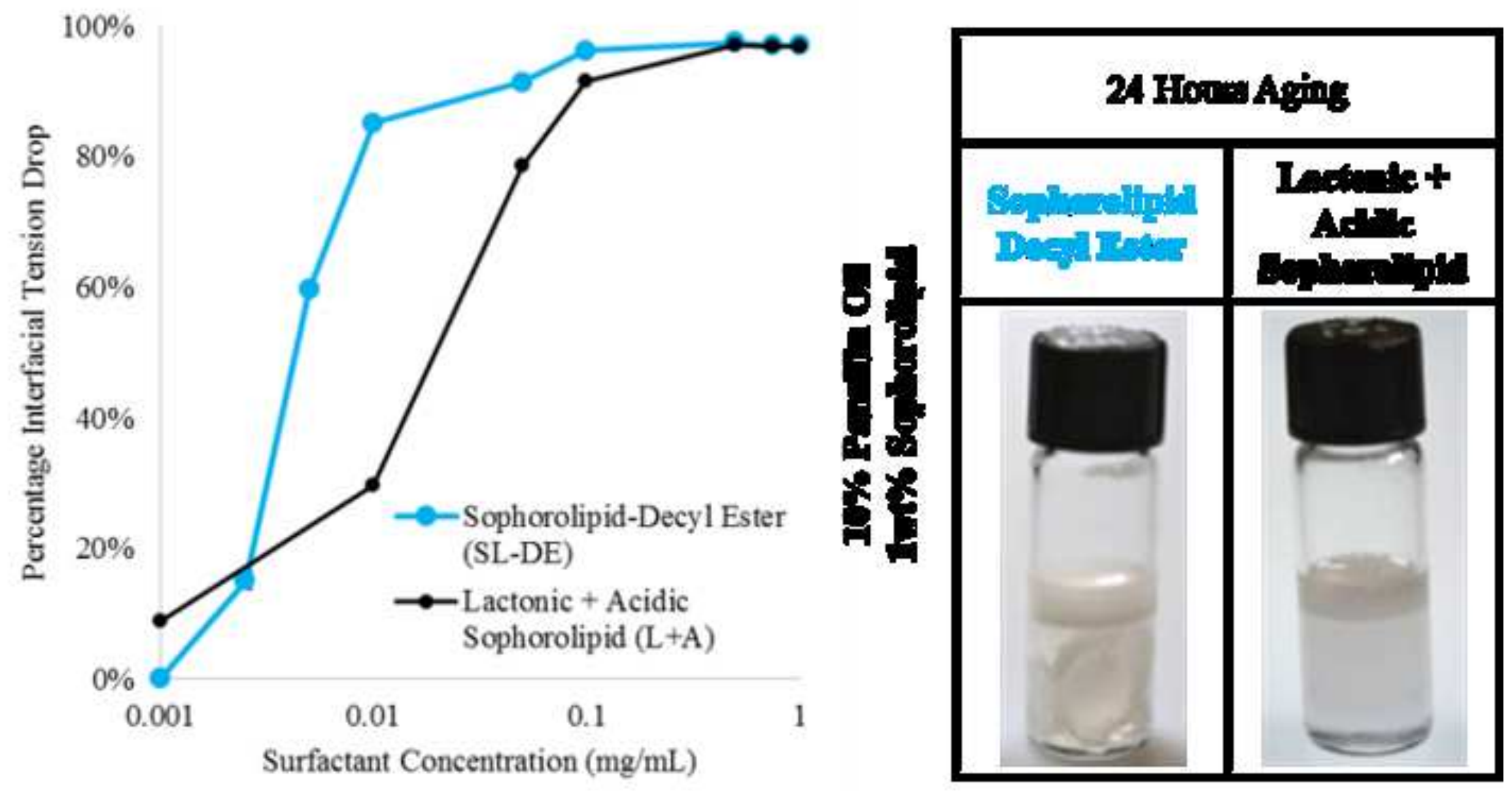


\title{
Molecular editing of sophorolipids by esterification of lipid moieties: effects on interfacial properties at paraffin and synthetic crude oil-water interfaces
}

\author{
Amanda Koh ${ }^{a}$ and Richard Gross ${ }^{a, b^{*}}$ \\ ${ }^{\mathrm{a}}$ Center for Biotechnology and Interdisciplinary Studies, Department of Chemical \& Biological Engineering, \\ Rensselaer Polytechnic Institute (RPI), Biotechnology Building, $1108^{\text {th }}$ Street, Troy, NY 12180 \\ ${ }^{\mathrm{b}}$ Center for Biotechnology and Interdisciplinary Studies, Department of Chemistry and Biology, Rensselaer \\ Polytechnic Institute (RPI), Biotechnology Building, $1108^{\text {th }}$ Street, Troy, NY 12180 \\ *Corresponding Author: Rensselaer Polytechnic Institute (RPI), Department of Chemistry and Biology, Center for \\ Biotechnology and Interdisciplinary Studies, Constellation Chair, 4005B BioTechnology Bldg, $1108^{\text {th }}$ Street, Troy, N.Y. \\ 12180. Phone: 518-276-3734, E-mail: grossr@rpi.edu
}

\begin{abstract}
Sophorolipids (SLs) are naturally produced glycolipid biosurfactants that offer safe alternatives to chemical surfactants that have been identified as ecologically-hazardous. Molecular editing of SLs by esterification of the lipid tail was used to prepare a family of SLesters whose hydrophobic moiety is extended from 18 carbons (17-HOC $\left.18: 1 \Delta^{9}\right)$ to 20, 24, or 28 carbons, respectively. The interfacial properties of natural and SL-esters were evaluated with paraffin and a synthetic crude oil. SL-esters reduced paraffin oil/water interfacial tension (IFT) by $89-97 \%$ and had critical aggregation concentrations (CACs) between $0.02-0.008 \mathrm{mg} / \mathrm{mL}$. SLesters were also found to emulsify paraffin and synthetic crude oil with oil/surfactant ratios up to 200:1 wt/wt for 1 week with emulsion droplet sizes below $5 \mu \mathrm{m}$. SL-hexyl ester had the lowest CAC, $0.008 \mathrm{mg} / \mathrm{mL}$, and generally, the lowest droplet sizes, particularly at $10 \mathrm{wt} \%$ paraffin oil. While, SL-decyl ester had the highest (97.2\%) maximum \%-IFT reduction and gave paraffin oil emulsions that were most stable over time. SL-ester emulsions of synthetic crude oil resulted in emulsion sizes that are similar to those with paraffin oil. However, the absence of SL-ester precipitation over the range of SL-ester/synthetic crude oil emulsions tested suggest that the affinity of SL-esters to the oil phase is enhanced by the presence of $o$-xylene and 1,2-
\end{abstract}


dimethylcyclohexane in the crude oil formulation. A natural SL mixture consisting of 1:1 lactonic (LSL) and acidic (ASL) forms has a CAC that is about an order of magnitude larger than SL-esters. Furthermore, the natural SL mixture was unable to emulsify paraffin and synthetic oil when the ratio of oil-to-surfactant is greater than 1:1. The predictive connection between CAC and emulsion sizes is discussed. IFT and emulsion data show that SL-esters are promising surfactants for crude oil related oil compositions.

Keywords: Sophorolipid, emulsion, interfacial tension, critical aggregation concentration, paraffin oil, crude oil ${ }^{1}$

\section{Introduction}

The study of mixing immiscible phases is critically important in living systems, the environment, and the development of commercial products. A mixed system of immiscible phases, however, is thermodynamically unstable with a high interfacial energy along the interface [1]. Surfactants, which adsorb at interfaces, reduce this energy and are used to control the properties of mixed systems.

The reduction of free energy in a mixed immiscible phase system is measured as reduction in surface or interfacial tension (IFT). Surfactant performance can be engineered to maximally decrease the interfacial energy between immiscible phases. Large markets for surfactants include personal care and crude oil, where, for the latter, oil drilling and oil spill clean-up are particularly important [2]. To best understand surfactant effectiveness for these

\footnotetext{
${ }^{1}$ Abbreviations: SL, sophorolipid, SL-EE, sophorolipid-ethyl ester, SL-HE, sophorolipid-hexyl ester, SL-DE, sophorolipid-decyl ester, LSL, lactonic sophorolipid, ASL, acidic sophorolipid, CAC, critical aggregation concentration.
} 
applications, this work focuses on paraffin oil/water interactions. Paraffin oil is often used as an emollient, thickener, and hydrophobic solubilizer in personal care applications such as shampoos and face creams [3]. Also, paraffin oil, or constituent alkanes, are often used in place of crude oil for petroleum related emulsification studies due to crude oil's high paraffinic content [4]. Effective surfactants must efficiently reduce the IFT of the emulsified oil. Furthermore, there is increasing concern about the toxicity of surfactants used for these applications. For example, after the Deep Water Horizon British Petroleum (BP) oil spill in 2010, 1.5 to 1.9 million gallons of dispersant, the majority of which was Corexit (product of Nalco Company), was employed to clean up the almost 5 billion gallons of spilled oil [5]. Research conducted since 2010 has shown that Corexit is bioaccumulative, cytotoxic, and generally toxic to aquatic ecosystems [5-6]. Safer non petrochemical-based surfactants with similar or better interfacial performance are needed to replace surfactants like Corexit.

For the reasons discussed above, biosurfactants are of interest as replacements for problematic petrochemical-derived surfactants. Biosurfactants are produced by microorganisms via fermentative processes and are non-toxic, biodegradable, and produced from readily renewable feedstocks [7]. There is a need to better understand biosurfactant interfacial performance, which will enable further engineering of biosurfactant structure to achieve desired physical properties.

Sophorolipids (SLs) are glycolipid biosurfactants produced by fermentation of yeasts such as Candida bombicola and Wickerhamiella domercqiae. The structure of natural SLs, as shown in Scheme 1, consists of sophorose (2-O- $\beta$-D-glucopyranosyl-D-glucose or $\beta$-D-Glc$(1 \rightarrow 2)$-D-Glc) bound to a hydroxyl fatty (e.g. 17-hydroxy-9-cis-octadecenoic acid, 17HOC $18: 1 \Delta^{9}$ ) through a glycosidic linkage. The sophorose group may be acetylated at the 6 ' 
and/or 6" positions. Natural sophorolipids consist of a mixture of lactonic (LSL, ring-closed) and acidic (ASL, ring-opened) molecules with varying degrees of acetylation [8].

Sophorolipids have already attracted commercial interest due to the availability of strains that are safe and result in relatively high SL yields (>400g/L) [9]. Current commercial producers/developers include Ecover (Belgium), Soliance/WheatOleo (France), Saraya (Japan), SyntheZyme (US), MG Intobio (South Korea), and Allied Carbon Solutions (ACS, Japan). The surface tension properties of natural sophorolipids have been previously evaluated. These studies have shown CMCs ranging from $20-130 \mathrm{mg} / \mathrm{L}$ and $\mathrm{mSFT}$ ranging from 32-42 $\mathrm{mN} / \mathrm{m}$ [10-13]. Hirata et al. studied the initial foaming performance of LSL [11]. Short-time aged emulsification of alkanes, fatty-acid based oils, isopropyl myristate, and benzene was studied by Daverey et al. and Ma et al $[12,13]$. IFT resulting from LSL at the water interface with hexane, heptane, sunflower oil, and olive oil was reported by Maddikeri et al. and Daverey et al $[12,14]$. However, these studies do not address the connection between IFT and emulsification nor did they focus on crude oil applications.

Molecular editing as used herein refers to systematic chemical modification of natural products. Through molecular editing, systematic studies can be performed to elucidate structureproperty relationships of closely related natural products. Hence, this approach provides a wide range of opportunities at the interface of biology and chemistry [15]. The Gross laboratory developed a set of simple and scalable natural SL post-modification reactions to comprehensively study natural and modified SL structure-property relationships. Of particular relevance to this work is the synthesis of SL-esters by LSL-ring opening under alkaline conditions using selected alcohols as both the solvent and reactant. By using ethanol, hexanol, and decanol, SL-ethyl ester (SL-EE), SL-hexyl ester (SL-HE), and SL-decyl ester (SL-DE) were 
prepared. Consequently, the SL hydrophobic moiety is extended from 18 carbons (17HOC $18: 1 \Delta^{9}$ ) to 20,24 , or 28 carbons, respectively [16]. The structure of these SL-esters is shown in Scheme 2. Indeed, the introduction of an ester between the 17-HOC18:1 $\Delta^{9}$ hydrophobic moiety and relatively shorter $n$-alkanol group is a unique structural feature of SL ester surfactants that differentiates it from other work where, for example, the fatty alcohol chain length of alkyl polyglucosides is varied [17].

There are few publications on SL-ester interfacial properties. Zhang et al. published mSFT and CMC values at $45^{\circ} \mathrm{C}$ for a series of $n$-alkyl esters where the $n$-alkyl length varied from methyl to hexyl. For example, SL-EE has a CMC of approximately $33 \mu \mathrm{M}$ and a mSFT of 38 $\mathrm{mN} / \mathrm{m}$ [18]. Shin et al. reported foaming, mSFT, and CMC values of SL-methyl ester [19]. Koh et al. reported emulsification and IFT at the almond oil/water interface as a function of SL-ester structure (SL-EE, SL-HE, and SL-DE) [20 Surfactant interfacial properties at oil-water interfaces are strongly dependent on the selected oil-phase, so this paper is focused on paraffin oil that significantly differs from almond oil and is an important component in applications (discussed above).

This paper reports on IFT reduction at the paraffin oil/water interface as a function of SL ester structure and concentration. Experimentally determined equilibrium IFT values were used to construct plots of percent IFT decrease vs. SL concentration. These plots were analyzed to determine the critical aggregation concentration (CAC) and maximum percentage IFT reduction (max \%-IFT). Dynamic IFT data was analyzed to determine diffusion coefficients at SL concentrations above and below their respective CACs. Foaming was studied as a function of paraffin oil and SL ester concentration. Furthermore, paraffin oil emulsification with varying SL ester structures and concentrations was analyzed over time to determine the stabilization 
effectiveness of SL esters. This was accomplished by tracking phase separation and measuring average droplet size. Also, to understand the effect of non-paraffinic crude oil components, emulsification studies with varying SL ester structures and concentrations was performed with a synthetic crude oil mixture having a composition that resembles Arabian crude oil.

\section{Materials and methods}

\subsection{Material Information}

Liquid paraffin oil was purchased from Sigma-Aldrich and purified of free surfactant following a published method [21]. For all studies performed herein, the paraffin oil used was from the same batch stored at room temperature. All water used for these experiments was Millipore de-ionized.

A synthetic crude oil was prepared to mimic the composition of Light Arabian crude oil [22]. It contains $63 \mathrm{wt} \%$ paraffin oil, $18 \mathrm{wt} \%$ 1,2-dimethylcyclohexane, and $19 \mathrm{wt} \% o$-xylene. The same synthetic crude oil batch was used for each experiment, mixed before each usage, and stored in a sealed jar to reduce evaporation. All components of the synthetic oil were purchased from Sigma-Aldrich in the highest available purity.

\subsection{Sophorolipid (SL) production via fermentation}

LSL was synthesized through fermentation of Candida bombicola as previously reported using high oleic acid content sunflower oil as the lipid source [23]. The crude sophorolipid mixture was extracted from the fermentation broth with ethyl acetate and the solvent was removed by rotary evaporation. The resulting solid that consisted primarily of residual fatty acids and SL's was dissolved in ethyl acetate to which an equal volume of warm hexane was 
added. The hexane/ethyl acetate solution was stored at $-20^{\circ} \mathrm{C}$ for $6 \mathrm{~h}$ after which the precipitate was filtered and dried. This was repeated until free fatty acids were removed and a mixture of LSL and ASL with varying degrees of acetylation remained (Scheme 1). Analysis of the mixture showed that its major constituent (approximately $95 \mathrm{~mol} \%$ ) is diacetylated LSL [8].

\subsection{Synthesis of SL-esters}

Sophorolipid modification to prepare SL-ethyl ester (SL-EE), SL-hexyl ester (SL-HE), and SL-decyl ester (SL-DE) was performed as previously reported [16]. Briefly, the synthesis of SL-DE was carried out by first reacting 1-decanol with sodium at $80^{\circ} \mathrm{C}$ for 3 hours to prepare a $0.2 \mathrm{~N}$ sodium decanoate in decanol solution. Natural sophorolipid $(2 \mathrm{~g})$ was treated with the sodium decanoate solution at $100^{\circ} \mathrm{C}$ for $12 \mathrm{~h}$. The reaction progress was tracked by thin layer chromatography (TLC) using a 8:2 v/v $\mathrm{CHCl}_{3}: \mathrm{MeOH}$ solution as eluent. Upon completion, the reaction mixture was acidified to $\mathrm{pH} 4$ with glacial acetic acid and purified by flash chromatography using $\mathrm{CHCl}_{3}: \mathrm{MeOH}$ as eluent. The structure of purified products was confirmed by Liquid Chromatography-Mass Spectrometry (LC-MS), ${ }^{1} \mathrm{H}$ NMR, and ${ }^{13} \mathrm{C}$ NMR that are identical to those previously reported $[16,20]$.

\subsection{Interfacial Tension (IFT)}

IFT was measured using a Krüss (Hamburg, Germany) DSA100 Drop Shape Analyzer at sophorolipid derivative concentrations from $0.001 \mathrm{mg} / \mathrm{mL}$ to $1 \mathrm{mg} / \mathrm{mL}$ for SL-EE, SL-HE, SLDE, ASL, and a 1:1 wt/wt LSL+ASL mixture. LSL was not measured due to poor solubility. Dynamic IFT measurements were analyzed at each concentration and for times required to reach equilibrium. For each water/oil/SL combination, diffusion coefficients were calculated from 
dynamic interfacial tension data using the short-time approximation (Equation 2) of Ward and Tordai's diffusion controlled adsorption relations shown in Equation 1 where:

$M=2 \sqrt{\frac{D}{\pi}} \int_{0}^{\sqrt{t}} \varphi(t) d \sqrt{t-\tau}$

$\frac{\gamma(t)-\gamma_{0}}{\sqrt{t}}=-2 R T C \sqrt{\frac{D_{a p}}{\pi}}$

$\mathrm{M}$ is surfactant concentration, $\mathrm{D}$ is diffusion coefficient, $\varphi$ is the surface surfactant concentration, and $\tau$ is a dummy integration variable. In Equation 2, $\gamma(\mathrm{t})$ is IFT at time $\mathrm{t}, \gamma_{\mathrm{o}}$ is the pure oil/water IFT ( $55.5 \mathrm{mN} / \mathrm{m}$ for paraffin oil used), $\mathrm{C}$ is the bulk surfactant concentration, and $\mathrm{D}_{\text {ap }}$ is the apparent diffusion coefficient [24, 25].

Equilibrium interfacial tension data was used to calculate the minimum interfacial tension achieved by a particular SL concentration and the critical aggregation concentration (CAC) for the SL/oil combination. The interfacial tension at each concentration is expressed as a percentage interfacial tension decrease calculated as shown in Equation 3:

$\%$ IFT Decrease $=\frac{\gamma_{0}-\gamma}{\gamma_{0}} * 100$

where $\gamma$ is the equilibrium interfacial tension at a particular SL concentration and $\gamma_{\mathrm{o}}$ is the pure oil/water interfacial tension. Minimum IFT values are the average of at least three consecutive IFT measurements in the high concentration-independent range. The CAC for each SL-ester is calculated as the intersection of the line drawn through at least three IFT points in the concentration-dependent range and the line drawn through at least three interfacial tension points in the concentration-independent range [26]. This is identical to how CMC values are calculated, however, as IFT values result from two, not one, self-interacting phases, the value is denoted as a CAC. CAC values are reported in $\mathrm{mg} / \mathrm{L}$ and mol/L for comparison between SL-esters. 


\subsection{Foaming}

The method for evaluating foaming is a modification of a literature procedure [27]. Foaming of $10 \mathrm{~g}$ solutions was performed using a standard glass column that is 18 inches long with a $1 / 2$ inch inner diameter and a stopcock. Weight percentages (relative to total solution weight) of solution constituents were 0.1 and $1 \%$ SL-ester or L+A with no oil and with 10 wt\% paraffin oil. The column was filled with the above $10 \mathrm{~g}$ solutions and air was bubbled through at a flow rate of $100 \mathrm{~mL} / \mathrm{min}$ until a foam height of $21 \mathrm{~cm}$ was reached (roughly three times the original liquid height). Air flow was controlled by an inline pressure gauge and flow meter. The foam height was measured every 60 seconds for one hour and measurements were performed three times for each solution. The effect of SL structure, concentration, and oil concentration on foam height and stability were evaluated.

\subsection{Emulsification}

Emulsions of paraffin oil were formed in de-ionized water using an IKA T25 Shear Homogenizer by mixing at 24,000 rpm for 60 seconds. Emulsions were made with oil concentrations of 1, 10, and $20 \mathrm{wt} \%$ and SL-EE, SL-HE, SL-DE, or L+A concentrations of 0.1 and $1 \mathrm{wt} \%$. All weight percentages are based on the total emulsion weight. Emulsions were analyzed immediately or allowed to age for $24 \mathrm{~h}$ and 1 week at $25^{\circ} \mathrm{C}$ in a temperature-controlled incubator before analysis. Emulsions of synthetic crude oil were homogenized in the same way with $10 \mathrm{wt} \%$ oil and either 0.1 or $1 \mathrm{wt} \%$ SL. Synthetic crude oil emulsions were analyzed immediately or allowed to age for $24 \mathrm{~h}$ and 1 week at $25^{\circ} \mathrm{C}$ before analysis.

Droplet size measurements were made with a Malvern Zetasizer ZSP (Worcestershire, UK) using a $173^{\circ}$ backscatter angle. All emulsions were diluted 100x with de-ionized water 
before analysis to avoid multiple scattering effects. Droplet sizes are reported as average droplet size (z-average) in nanometers. Emulsion phase stability was tracked over time and photographs were taken with a Nikon D5200 camera with a Nikon AF-S Micro Nikkor 60mm lens at each analyzed time point.

\section{Results and Discussion}

\subsection{Effect of sophorolipid structure and concentration on IFT}

Surfactants, as amphiphilic molecules, are characterized by their preferential adsorption to hydrophilic/lipophilic interfaces. To minimize interfacial free energy, surfactants orient such that their hydrophilic regions interact with the hydrophilic phase, and the lipophilic regions interact with the lipophilic phase. The interfacial free energy is characterized by the equation:

$\Delta \mathrm{G}=\gamma \Delta \mathrm{A}$

where $\Delta \mathrm{A}$ is the change in interfacial area, and $\gamma$ is the IFT of the lipophilic/hydrophilic interface [1]. Thus, a surfactant may decrease the interfacial free energy of a system by decreasing the interfacial tension.

Similar to surface tension, interfacial tension is dependent upon a number of formulation and environmental parameters such as surfactant structure and concentration. As the surfactant concentration increases it adsorbs onto the interface and decreases the IFT. At a particular concentration, herein called the critical aggregation concentration (CAC), the surfactant has saturated the oil/water interface and begins forming micellar aggregates in the bulk water solution. Above the CAC, the total surfactant concentration at the interface does not increase and the IFT reaches a minimum [26]. 
In Figure 1, the interfacial tension reduction at the oil/water interface is shown across SLester concentrations from 0.001 to $1 \mathrm{mg} / \mathrm{mL}$. The upper concentration range tested was restricted by SL-ester solubility. Analogous to published SL-ester data for the almond oil/water interface, SL-HE and SL-DE show similar \%-IFT reduction vs. concentration curves while SL-EE shows a slower increase in equilibrium \%-IFT reduction and reaches a lower max \%-IFT reduction [20]. Table 1 lists max \%-IFT and CAC for each SL-ester. Max \%-IFT reduction increased from 89.2\% for SL-EE to 95.2 and 97.2 for SL-HE and SL-DE, respectively. Molar and weight CAC values followed a different trend decreasing from $0.020 \mathrm{mg} / \mathrm{mL}$ for SL-EE to 0.011 and 0.008 for SL-DE and SL-HE, respectively. The CAC of SL-EE is more than twice that of SL-HE. This means that SL-EE relative to SL-HE needs twice as much surfactant to saturate the paraffin oil/water interface to reach a relatively lower max \%-IFT. In summary, SL-EE is the least effective of the SL-esters at reducing IFT. SL-HE requires the lowest quantity of surfactant to reach its max \%-IFT reduction and SL-DE attains the highest max \%-IFT reduction.

Figure 1 also shows the IFT vs. concentration for L+A and ASL. The L+A curve is shifted to higher concentrations, indicating its CAC is higher than the SL-esters. However, the max \%-IFT reduction for $\mathrm{L}+\mathrm{A}$ is similar to SL-DE. The CAC of $\mathrm{L}+\mathrm{A}$ is $0.099 \mathrm{mg} / \mathrm{mL}$ which is about five times that of SL-EE, the next lowest performing SL-ester (Table 1). The IFT of ASL was measured up to $50 \mathrm{mg} / \mathrm{mL}$ and, although the data in Figure 1 is only shown to $1 \mathrm{mg} / \mathrm{mL}$, the ASL CAC is $1.2 \mathrm{mg} / \mathrm{mL}$ while the max $\%$-IFT is $79.9 \%$. The ASL CAC is two orders of magnitude larger than the SL-esters, indicating that a much higher concentration of ASL is needed to stabilize the same amount of interface. This may be due to the increased solubility of ASL leading to a higher concentration remaining in bulk solution. ASL also has the lowest max 
$\%$-IFT of the SLs measured, $10 \%$ lower than SL-EE, indicating that, relative to the SL-esters, ASL has a lower potential for paraffin oil emulsion stabilization.

Extensive work has been published on determining IFT values at paraffinic and single $n$ alkane oil/water interfaces. Natural SL mixtures were found to reduce $n$-hexane, $n$-heptane, and $n$-hexadecane IFT to $0.99 \mathrm{mN} / \mathrm{m}$ (at $0.2 \mathrm{mg} / \mathrm{mL}$ ), $1.4 \mathrm{mN} / \mathrm{m}$ (at $0.5 \mathrm{mg} / \mathrm{mL}$ ), and $5 \mathrm{mN} / \mathrm{m}$ (at 0.1 $\mathrm{mg} / \mathrm{mL}$ ), respectively $[12,14,28]$. These values are generally similar to those published for other surfactants such as Span 80 and lecithin [29]. However, currently there are no reports on IFT reduction by SLs with paraffin oil. Apenten et al. found that, for paraffin oil, Span 80 and Tween 80, two non-ionic surfactants, had CAC's of $2.3 \times 10^{-3} \mathrm{M}$ and $2 \times 10^{-4} \mathrm{M}$ and reduced IFT's by 43 and $31.4 \mathrm{mN} / \mathrm{m}$, respectively [30]. Santini et al. also studied Span 80 and reported minimum IFT and CAC values at the paraffin/water interface of $3.0 \mathrm{mN} / \mathrm{m}$ and $4.3 \times 10^{-4} \mathrm{M}$, respectively [31]. The difference in reported CAC values between these two studies may be due to Span 80s solubility in oil and the way in which the measurements were performed (e.g. De Nouy ring vs. drop shape analysis). Niraula et al. determined minimum IFT and CAC values at paraffin oil/water interfaces with a series of surfactants that possess a 12-carbon alkyl hydrophobic tail and varying polar head groups. With maltose, sucrose, ethylene oxide, and sulfate polar head groups, the CAC's are $1.6 \times 10^{-4} \mathrm{M}, 3.8 \times 10^{-4} \mathrm{M}, 9.1 \times 10^{-5} \mathrm{M}$, and $8.3 \times 10^{-3} \mathrm{M}$, respectively, and the minimum IFT values are $28.3 \mathrm{mN} / \mathrm{m}, 29.64 \mathrm{mN} / \mathrm{m}, 29.3 \mathrm{mN} / \mathrm{m}$, and 32.0 $\mathrm{mN} / \mathrm{m}$ [32]. In comparison, SL-HE has CAC and minimum IFT values of $1.1 \times 10^{-5} \mathrm{M}$ and 1.6 $\mathrm{mN} / \mathrm{m}$, respectively. Hence, SL-HE outperforms the above commercial polymeric and smallmolecule surfactants. In contrast, ASL and the natural 1:1 L+A SL mixture generally show poorer performance relative to the above commercial surfactants for stabilizing paraffin oil/water interfaces. 


\subsection{Effect of sophorolipid structure on dynamic IFT}

The max \%-IFT and CAC discussed above are representative of the SL-ester equilibrium IFT. To gain a better understanding of SL-ester interactions at the oil/water interface, dynamic IFT measurements (i.e. IFT vs. time ${ }^{1 / 2}, \mathrm{t}^{1 / 2}$ ) was analyzed. Dynamic IFT was measured for each SL-ester, ASL, and L+A at concentrations from 0.001 to $1 \mathrm{mg} / \mathrm{mL}$. Plots of IFT vs. $\mathrm{t}^{1 / 2}$ are displayed in Figure 2 for SL concentrations of $0.001,0.01,0.1$, and $1 \mathrm{mg} / \mathrm{mL}$. Diffusion coefficients were calculated using data from the initial linear portion of plots of IFT vs $\mathrm{t}^{1 / 2}$. The slope of the linear region was calculated from a linear regression fit of at least three data points $\left(\mathrm{R}^{2}>0.9\right)$ and used in Equation (2) to calculate the diffusion coefficient.

Figure 3(a) shows diffusion coefficients vs. concentration for SL-EE, SL-HE, and SLDE. At concentrations $\leq 0.01 \mathrm{mg} / \mathrm{mL}$, SL-EE has the highest diffusion coefficient, which is attributed to its short $n$-alkyl ester chain length. After the SL-EE CAC $(0.02 \mathrm{mg} / \mathrm{mL})$ the diffusion coefficient decreases. This trend is also seen for SL-DE, CAC of $0.011 \mathrm{mg} / \mathrm{mL}$, although the decrease in the diffusion coefficient is significantly slower than that for SL-EE and SL-HE. This is reflected in the Figure 2, in which SL-DE consistently takes longer to reach equilibrium than SL-EE or SL-HE. SL-HE shows a much broader peak than SL-EE and SL-DE with a decrease in diffusion coefficient that occurs at concentrations above its CAC (0.080 $\mathrm{mg} / \mathrm{mL})$.

The consistent decrease in the diffusion coefficient of SL-esters for concentrations above the CAC is attributed to crowding and increased repulsion between polar SL head groups at the oil/water interface. At a SL concentration below the CAC, the oil/water interface is not yet saturated and it is energetically favorable for the surfactant to adsorb to the interface. Above the 
CAC, the oil/water interface becomes saturated such that further increases in surfactant concentration at the interface require unfavorable interactions between SL molecules.

At concentrations above $0.1 \mathrm{mg} / \mathrm{mL}$, decrease in the diffusion constants of SL-HE and SL-EE are similar in value and decrease at comparable rates with SL concentration. At these concentrations, SL-DE shows diffusion coefficients that are two to three orders of magnitude higher than SL-EE and SL-HE. This observed higher diffusion rates of SL-DE does not correlate with improved CAC or max \%-IFT relative to SL-EE and SL-HE, suggesting that SL-DE adsorption to the oil/water interface is kinetically controlled. This may also result in the longer times to reach equilibrium mentioned previously.

Figure 3(b) shows the diffusion coefficients of ASL and LSL + ASL 1:1 wt/wt from 0.01 to $50 \mathrm{mg} / \mathrm{mL}$ and 0.001 to $1 \mathrm{mg} / \mathrm{mL}$, respectively. Similar to the SL-esters, LSL+ASL has high diffusion coefficient values below its CAC $(0.099 \mathrm{mg} / \mathrm{mL})$ that decrease at concentrations above its CAC. The slope of the decrease in diffusion coefficient of LSL+ASL above its CAC is similar to that of SL-DE and, therefore, higher than those of SL-EE and SL-HE at concentrations $>0.1 \mathrm{mg} / \mathrm{mL})$. ASL shows no peak or change in slope around its CAC $(1.26 \mathrm{mg} / \mathrm{mL})$ and the decrease in its diffusion coefficient above $0.1 \mathrm{mg} / \mathrm{mL}$ is similar to that of SL-EE and SL-HE. This suggests there is a critical SL $n$-alkyl ester chain length that is between 6 and $10 \mathrm{CH}_{2}$ units, where adsorption is diffusion-controlled.

\subsection{Sophorolipid Ester Foaming}

Foaming is a fundamental surfactant performance characteristic. Measurement of foaming with and without the oil-phase provides a better understanding of a surfactants foaming potential for crude oil recovery and clean-up [27]. Increased bubble formation and stability 
reflects a better ability of a surfactant to decrease the air/water surface tension. In other words, the foam lifetime is directly related to the surfactant surface tension effectiveness. In the presence of oil, the interfacial tension decrease between oil and water will also be an important factor influencing foam performance and lifetime. LSL is known to exhibit poor foaming capability without oil, while ASL is a good foam stabilizer without oil [11]. The foaming properties of SL-esters and natural SLs with paraffin oil have not yet been reported.

Figure 4 shows the initial and final foam heights of SL-ester solutions with and without oil at either 0.1 or $1 \mathrm{wt} \% \mathrm{SL}$. Initial foam height is defined as the foam height after 60s as all foam measurements were standardized to a height of $21 \mathrm{~cm}$ at time 0 . Data in Figure 4(a) and (b) show the initial foam heights of SL-ester solutions with 0 and $10 \mathrm{wt} \%$ paraffin oil, respectively. At $0 \mathrm{wt} \%$ oil, the initial foam heights vary from 12.7 to $14.6 \mathrm{~cm}$. Thus, there is little variation in foam heights at $0 \mathrm{wt} \%$ oil across SL-ester concentrations and structures. At 10 wt $\%$ oil, the initial foam height for SL-HE and SL-DE at $1.0 \mathrm{wt} \%$ is slightly higher than at 0.1 $\mathrm{wt} \%$ and all foam heights range from 12.5 to $16.0 \mathrm{~cm}$. There is no consistent trend in the initial foam height when comparing solutions with 0 and $10 \mathrm{wt} \%$ paraffin oil. Furthermore, overall, differences in initial foam height are small over the range of SL-ester structures, concentrations and with the presence or absence of paraffin oil.

Final foam height is defined as the foam height measured 60 minutes after air was bubbled through the solution. Figures 4(c) and (d) show the final foam heights measured for SLester solutions with 0 and $10 \mathrm{wt} \%$ paraffin oil, respectively. For solutions with $0 \mathrm{wt} \%$ paraffin oil, the order of increasing foam height for both 0.1 and $1.0 \mathrm{wt} \%$ SL-ester is SL-EE $\approx \mathrm{SL}-\mathrm{HE}<\mathrm{SL}-$ DE. Values of final foam height with $0 \mathrm{wt} \%$ paraffin range from $0.7 \mathrm{~cm}$ for $1.0 \mathrm{wt} \% \mathrm{SL}-\mathrm{EE}$ to $11.4 \mathrm{~cm}$ for $0.1 \mathrm{wt} \%$ SL-DE. A decrease in final foam height with an increase in SL 
concentration was seen for SL-EE and SL-DE while the final foam height of SL-HE showed no significant dependence on SL concentration. A decrease in foam height with increasing surfactant concentration is often attributed to a reduction in interfacial elasticity which reduces foam thin film stability [33]. Results in Figure 4(d) show that, regardless of SL-structure and concentration, the addition of $10 \%$ paraffin oil to solutions results in poor foam stabilization. Reduction of foam height due to the presence of oil is in agreement with published results using AOT, a high foaming surfactant, and various alkanes [27]. Under these conditions, SL-DE shows the highest final foam height $(3 \mathrm{~cm}$ at $0.1 \mathrm{wt} \%)$. The final foam height with paraffin oil matches the trend in max \%-IFT reduction. The most striking results from Figure $4 \mathrm{c}$ and $4 \mathrm{~d}$ is the large decrease in foam height at all SL-ester concentrations and ester structure with the addition of paraffin oil at $10 \mathrm{wt} \%$ to solutions. The final foam height for SL-EE is reduced to 0 $\mathrm{cm}$ and the final foam height for SL-DE and SL-HE is reduced by approximately $70 \%$.

Figure 4 also shows foaming characteristics of L+A at 0.1 and $1.0 \mathrm{wt} \%$ with 0 or $10 \mathrm{wt} \%$ paraffin oil. Figure 4(a) and (b) show lower initial foam heights for L+A relative to the SLesters, particularly in the presence of oil. Figure 4(c) also shows lower final foam heights for $\mathrm{L}+\mathrm{A}$ as compared to the SL-esters. Complete foam collapse for L+A with $10 \%$ paraffin occurred in only 4 min whereas, SL-EE, the next lowest performing SL, required 33 minutes for foam collapse. Hirata et al. showed significantly more persistent foam than what is reported herein (Figure 4) [11]. They used an unpurified 7:3 mixture of LSL:ASL with no oil, suggesting that components from an unpurified fermentation mixture may improve $\mathrm{L}+\mathrm{A}$ foaming performance. Results herein show that initial foaming by $\mathrm{L}+\mathrm{A}$ is an order of magnitude lower than surfactin, Pluronic L31, and sodium dodecyl sulfate [11]. Since initial foaming of L+A was not an order of magnitude lower than the SL-esters, it follows that SL-esters are lower foaming 
performers than surfactin, Pluronic L31, and sodium dodecyl sulfate. Thus, while all SL-esters showed significantly improved ability to support foam formation relative to the natural SL mixture, SLs in general are not high performance foamers.

\subsection{Paraffin Oil Emulsification by SL-Esters}

Emulsions of 1, 10, and 20wt\% paraffin oil were made with 0.1 and $1.0 \mathrm{wt} \%$ SL-ester. Emulsions were analyzed immediately after homogenization as well as after $24 \mathrm{~h}$ and 1 week of aging at $25^{\circ} \mathrm{C}$. Figure 5 shows the average emulsion droplet sizes of the emulsions at each time point. For analyses immediately after homogenization, droplet sizes are relatively similar across surfactant structures and oil concentration at both SL concentrations. At 0.1wt\% SL and 10wt\%, the droplet size immediately after homogenization is smallest for SL-EE and increased for SLHE and SL-DE. However, this may be due to foaming as this is also the trend in foam height (Figure 4b). The other two oil concentrations immediately after homogenization at $0.1 \mathrm{wt} \%$ SL showed no significant differences in average emulsion droplet size as a function of SL-ester structure. After aging for $24 \mathrm{~h}$, a time that all foam should have dissipated based on Figure $4 \mathrm{~d}$, the emulsion droplet size trend at 0.1 and $1 \mathrm{wt} \%$ SL, particularly at $10 \mathrm{wt} \%$ paraffin oil, is SL$\mathrm{HE}<\mathrm{SL}-\mathrm{DE}<\mathrm{SL}-\mathrm{EE}$. The lower CAC of SL-HE is consistent with this trend (Table 1). Indeed, the SL-ester with the lowest CAC requires the least surfactant per unit interface. Since all emulsions were homogenized at the same speed for the same amount of time, the same amount of oil/water interface would have been available to all three SL-esters. SL-HE, which can stabilize the most interface for the same SL concentration, should then have the smallest droplets. 
After 1 week of aging, emulsion droplet sizes of SL-HE and SL-DE are similar, except at $1 \mathrm{wt} \% \mathrm{SL}$ and $20 \mathrm{wt} \%$ oil. This behavior is explained by that long term stability of paraffin oil emulsions is dependent on both the CAC for initial emulsion droplet size, and max \%-IFT reduction for effective interface stabilization. This is also reflected in SL-ester emulsion sizes over time. For example, SL-DE, which has the highest max \%-IFT reduction, shows the smallest change in size over time. Average emulsion droplet sizes grouped by aging time point are shown in the supporting information. SL-EE has the largest average emulsion droplet size at 1 week with $1 \mathrm{wt} \% \mathrm{SL}$, as is expected from the IFT data. From 24 hours to 1 week at $0.1 \mathrm{wt} \% \mathrm{SL}$, the emulsion droplet sizes for SL-EE decrease due to oil separation from these emulsions that is visually observed but not obvious from the recorded photographic images.

Emulsion sizes for SL-esters are generally comparable or outperform comparable surfactants in the literature. Dodecyl maltoside and sucrose dodecanoate, sugar-based non-ionic surfactants, formed emulsions with average sizes of $5.36 \mu \mathrm{m}$ and $5.64 \mu \mathrm{m}$, respectively, at $0.012 \mathrm{M}$ with $20 \%$ paraffin oil [32]. Hydroxypropyl methyl cellulose at a concentration $1 \mathrm{mg} / \mathrm{mL}$ and $40 \%$ paraffin oil formed emulsions with an average size of $107 \mu \mathrm{m}$ although this may be because the method of particle stabilization is different than that of a small molecule surfactant [34]. Span 80, lecithin, and polyglycerol polyricinoleate (PGPR) formed average emulsion sizes of $3.74,38.23$, and $5.29 \mu \mathrm{m}$ with $30 \%$ hexadecane [29].

Figure 6 shows average emulsion droplet sizes for emulsions of 0.1 and 1 wt $\%$ L+A with 1, 10, and $20 \mathrm{wt} \%$ paraffin oil. Emulsions with $0.1 \mathrm{wt} \% \mathrm{~L}+\mathrm{A}$ show almost no change in oil droplet size after $24 \mathrm{~h}$ at all three oil concentrations and a slight increase in droplet size after aging for 1 week. However, oil separation is observed for $0.1 \mathrm{wt} \% \mathrm{~L}+\mathrm{A}$ emulsions at 1, 10, and $20 \mathrm{wt} \%$ oil (see Table 2). Consequently, the average droplet sizes in Figure 6a are smaller than 
0.1wt\% SL-ester stabilized emulsions that did not undergo oil separation and look similar to $0.1 \mathrm{wt} \%$, but not $1 \mathrm{wt} \%$, SL-EE after one week. These results are consistent with L+A CAC values that are five times higher than the SL-EE, which has the highest CAC of the SL-esters studied herein. For paraffin emulsions formed with $1 \mathrm{wt} \% \mathrm{~L}+\mathrm{A}$, oil droplet size increases with oil concentration and oil separation is evident. Precipitation occurs at 0.1 and 1 wt $\%$ SL, presumably due to the low solubility of LSL [35]. Hence, what starts as a 1:1 L+A mixture become enriched in the ASL component whose CAC is about 13 times higher than L+A.

\subsection{Synthetic Crude Oil Emulsification}

One use of paraffin oil is to mimic crude oil in emulsification experiments [4]. This is often a consequence of numerous difficulties encountered when using crude oil such as high viscosity, an uncertain and unstable composition, and toxic components [22]. As crude oil emulsification is a primary approach used in processes for oil spill cleanup [36], the efficiency of crude oil emulsification by SL-esters is of high interest. To address this question, a synthetic crude oil was formulated to mimic the composition of Light Arabian crude oil [22]. The synthetic crude oil contains paraffin oil (67 wt \%), $o$-xylene (19 wt\%) and 1,2dimethylcyclohexane (18 wt\%). These components were selected to mimic the paraffinic, aromatic and napthalenic fractions, respectively. The emulsions were prepared and analyzed similarly to paraffin oil emulsions. They were made with $10 \mathrm{wt} \%$ synthetic crude oil and 0.1 or $1.0 \mathrm{wt} \%$ SL. Average emulsion droplet sizes shown in Figure 7 were measured immediately after homogenization, after aging for 24 hours and 1 week at $25^{\circ} \mathrm{C}$. Furthermore, emulsions were photographed to record phase stability. 
At $0.1 \mathrm{wt} \%$ SL, all three SL esters perform similarly for synthetic crude oil emulsification. Emulsion droplet sizes are larger with synthetic crude oil than paraffin oil. However, the overall change in emulsion droplet size with time for synthetic crude oil is much smaller, indicating these emulsions have useful long-term stability. After aging for 1 week at $1 w t \%$ SL-ester concentrations, the average droplet sizes of SL-EE increased from about $2.3 \mu \mathrm{m}$ to $4 \mu \mathrm{m}$. In contrast, up to 1 week, the average droplet sizes of SL-HE and SL-DE remained nearly constant. Hence, at $1 \mathrm{wt} \%$, SL-EE stabilization of synthetic crude oil was less effective than SL-HE and SL-DE. Comparing the two oils, SL-DE at 1wt\% shows similar performance whereas SL-HE is more stable over time for synthetic crude oil. The same stability trend is also seen for $0.1 \mathrm{wt} \%$ SL-HE and SL-DE.

After aging for $24 \mathrm{~h}$ and 1 week, the physical stability of $10 \mathrm{wt} \%$ paraffin oil and synthetic crude oil emulsions was visually analyzed and photographed (Table 2). The photographs were not recorded immediately after homogenization due to foaming. All emulsions, regardless of oil composition or surfactant structure, exhibit significant creaming. For SL-ester emulsions, the emulsion phases remain unchanged with no oil separation over 1 week indicating emulsion stability. SL-ester precipitation is observed for each of the three $1 \mathrm{wt} \% \mathrm{SL}-$ ester/paraffin oil emulsions aged for 24 hours and 1 week. Furthermore, after aging the 0.1 wt $\%$ SL-DE/paraffin oil emulsion for 1 week, SL-DE precipitation was observed. This indicates that oil-SL interactions are not sufficiently strong to overcome low SL-ester solubility. In contrast, for SL-ester/synthetic crude oil emulsions, precipitation even at $1 \mathrm{wt} \%$ surfactant concentration and aging for 1 week was not observed. This suggests that the affinity of SL-esters for the hydrophobic phase was enhanced by incorporation of 1,2-dimethylcyclohexane and $o$-xylene in paraffin oil. This result is consistent with the observed improved stabilization based on oil 
droplet size measurements over time by SL-esters of emulsions consisting of the synthetic oil relative to neat paraffin. Hence, SL-esters are a promising family of surfactants for crude oil emulsions.

The ability of the L+A 1:1 w/w natural sophorolipid mixture to stabilize paraffin and synthetic crude oil emulsions was compared to the results obtained with SL-esters. Average droplet sizes of L+A/synthetic crude oil emulsions were smaller than those with SL-esters. This is attributed to oil separation that was present at $0.1 \mathrm{wt} \%$ but most apparent for $1 \mathrm{wt} \% \mathrm{~L}+\mathrm{A}$ emulsions (Table 2). Synthetic crude oil emulsions with 1 wt $\%$ L+A show almost complete oil separation after 1 week while $0.1 \mathrm{wt} \%$ L+A emulsions still exhibit an emulsion phase with oil separation after 1 week. Precipitation was also seen for L+A synthetic crude oil emulsions. This is in contrast to paraffin oil emulsions, which exhibited significantly less oil separation. Oil separation, particularly at $1 \mathrm{wt} \% \mathrm{SL}$, is reflected in the relative emulsion droplet sizes where $0.1 \mathrm{wt} \%$ sizes for L+A are similar across the two oils whereas synthetic crude oil shows smaller sizes. Results shown in Figure 7 and Table 2 show this natural surfactant mixture exhibited poor stabilization of emulsions. This could in part be due to charge-charge repulsion between ASL fatty acids moieties that counteract potential interfacial stabilization.

SL emulsification performance of the synthetic crude oil used herein is compared to literature reports with petroleum-derived oils that differ in composition. Bąk et al. showed that Tween 80 forms emulsions of $5 \%$ toluene with sizes of $\geq 50 \mu \mathrm{m}$ although the emulsions were formed at relatively lower homogenizer mixing speed and with lower concentrations of at much lower surfactant concentrations and homogenization speeds than what were used in this discussion [37]. Toluene is a simple mono-substituted aromatic that is often found in crude oil and has a similar structure to $o$-xylene used herein as component in the synthetic crude oil 
system. Abismail et al. emulsified $25 \%$ kerosene with $10 \mathrm{mg} / \mathrm{mL}$ of Tween 60 and formed emulsions with sizes around $2 \mu \mathrm{m}$ [1]. Kerosene is also a mixture of paraffinic, napthalenic, and aromatic components although of a different composition than crude oil and the synthetic crude oil used herein. Kundu et al. emulsified 30\% diesel oil with sodium dodecyl benzene sulfonate where the surfactant-to-oil ratio is 0.1 . They formed emulsions with average sizes of about 26 $\mu \mathrm{m}$ and reported being unable to make emulsions at lower surfactant to oil ratios such as those tested in this work [38]. Keeping in mind that these literature reports were performed with different petroleum-derived oil phases than those used herein, comparison to the SL-ester emulsion and IFT results indicate that SL-esters are able to emulsify synthetic crude oil comparably or better than the above described commercial surfactants. However, L+A was unable to completely emulsify synthetic crude oil at any of the conditions mentioned in the above cited literature, and, therefore, is expected to be a poorer performer than the comparative surfactants.

\section{Conclusions}

Studies were performed to determine interfacial tension, foaming, and emulsification performance as a function of SL structure and concentration. SL-esters, particularly SL-HE and SL-DE, are effective emulsifiers of paraffin oil and a synthetic crude oil designed to mimic Light Arabian crude. SL-HE and SL-DE emulsify paraffin and synthetic crude oil at concentrations up to 200 times that of the surfactant. Paraffin oil emulsions formed with SL-HE have the smallest emulsion droplets relative to those resulting from emulsions created using the other SL surfactants studied herein. The fact that SL-HE also has the lowest CAC of the SL surfactants is consistent with that CAC is a predictor of surfactant performance at oil/water interfaces. SL-DE, 
which results in the highest max \%-IFT (97\%), forms paraffin oil/water emulsions with droplet sizes that were most stable over time. These trends were also seen in emulsions of synthetic crude oil.

Precipitation was consistently observed for the three $1 \mathrm{wt} \%$ SL-ester/paraffin oil emulsions aged for 24 hours and 1 week. In contrast, precipitation under these conditions for SLester/synthetic crude oil emulsions was not observed. This suggests that the affinity of SL-esters for the hydrophobic phase is enhanced by incorporation of 1,2-dimethylcyclohexane and $o$ xylene (components of synthetic crude oil) in paraffin oil.

A natural 1:1 wt/wt mixture of LSL and ASL was also evaluated as emulsifiers for paraffin and synthetic crude oil. IFT measurements showed that the CAC of L+A is an order of magnitude higher than that of the SL-esters. However, the max \%-IFT reduction attained with $\mathrm{L}+\mathrm{A}$ is similar to that of SL-HE and SL-DE. As predicted by relative CAC values, SL-esters are more efficient than $\mathrm{L}+\mathrm{A}$ in paraffin oil emulsion stabilization. This is evident by oil separation in $\mathrm{L}+\mathrm{A} /$ paraffin emulsions, even at $0.1 \mathrm{wt} \%$ surfactant. Furthermore, synthetic crude oil emulsions with $1 \mathrm{wt} \% \mathrm{~L}+\mathrm{A}$ show almost complete oil separation after 1 week. These results highlight the potential of improving interfacial performance of sophorolipids by molecular editing of the natural products via simple chemical modifications.

The foaming performance of SL-ester and L+A was also investigated in the presence of and without paraffin oil. SL-esters generally outperformed L+A in foam height and longevity. However, based on literature studies of high foaming surfactants, SL-esters are still relatively poor foam stabilizers.

This work highlights the dual potential for modified sophorolipids in paraffin oil and crude oil based applications. Modified sophorolipids were seen to be comparable or outperform 
common commercial surfactants with paraffin oil, and perform similarly to literature reported emulsions of crude oil-based hydrophobic phases (ie. kerosene). This makes them an excellent option for replacing current ecologically harmful surfactants. It is also seen that the performance of the modified sophorolipids, whether it be emulsification, foaming, or interfacial tension, can be tuned based on simple hydrophobic tail structure modifications. This makes modified sophorolipids an exciting platform for the emulsification of a wide variety of hydrophobic phases, which is important considering the wide variety in compositions of crude oils and crude oil derivatives. Future work with modified sophorolipids will include a wider range of synthetic crude oil compositions. Thus, measurements of IFT, corresponding CAC and emulsion stabilization will be conducted with a series of synthetic crude oils with systematic changes in the composition. We expect that with more information on the impact of different structures, modified sophorolipids could be developed and optimized for a wide variety of oil compositions. Furthermore, the range of modified SL's included in interfacial property studies and the environmental parameters of the systems tested (i.e. temperature, salinity, etc.) will be expanded to further refine our understanding of sophorolipid structure-interfacial property relationships.

\section{Acknowledgements}

The authors are grateful for funding received from the National Science Foundation Partnerships for International Research and Education (PIRE) Program (Award \#1243313).

\section{References}

(1) Abismaïl, B., Canselier, J. P., Wilhelm, A. M., Delmas, H., Gourdon, C., Emulsification by ultrasound: drop size distribution and stability. Ultrasonics Sonochemistry, 1999, 6, 75-83. 
(2) Ghannam, M., Water-in-Crude Oil Emulsion Stability Investigation. Petroleum Science and Technology 2005, 23, 649-667.

(3) Rawlings, A. V., Lombard, K. J., A review on the extensive skin benefits of mineral oil. International Journal of Cosmetic Science, 2012, 34, 511-518.

(4) Schulz, E., Ambrusi, R., Miraglia, D., Schulz, E., García, S., Rodriguez, J., Schulz, P., Evaluation of oil-in-water emulsions with cationic-anionic surfactants mixtures for potential use in the oil industry. Colloids and Surfaces A: Physiochemical and Engineering Aspects, 2016, 490, 145-154.

(5) Zheng, M., Ahuja, M., Bhattacharya, D., Clement, T., Hayworth, J., Dhanasekaran, M., Evaluation of differential cytotoxic effects of the oil spill dispersant Corexit 9500. Life Sciences, 2014, 95, 108-117.

(6) Almeda, R., Hyatt, C., Buskey, E., Toxicity of dispersant Corexit 9500A and crude oil to marine microzooplankton. Ecotoxicology and Environmental Safety, 2014, 106, 76-85.

(7) Marchant, R., Banat, I., Biosurfactants: a sustainable replacement for chemical surfactants? Biotechnol Lett, 2012, 34, 1597-1605.

(8) Ratsep, P., Shah, V., Identification and quantification of sophorolipid analogs using ultra-fast liquid chromatography-mass spectrometry. Journal of Microbiological Methods., 2009, 78, 354-356.

(9) Van Bogaert, I., Saerens, K., Muynck, C.D., Develter, D., Soetaert, U. and Vandamme, E.J., Microbial production of application of sophorolipids. Appl. Microbiol. and Biotech. 2007, 76, 23-34.

(10) Mulligan, C., Environmental applications for biosurfactants. Environmental Pollution, 2005, 133, 183-198. 
(11) Hirata, Y., Ryu, M., Oda, Y., Igarashi, K., Nagatsuka, A., Furuta, T., Suguira, M., Novel characteristics of sophorolipids, yeast glycolipid biosurfactants, as biodegradable lowfoaming surfactants. Journal of Bioscience and Bioengineering 2009, 108, 142-146.

(12) Daverey, A., Pakshirajan, K., Sophorolipids from Candida bombicola using mixed hydrophilic substrates: Production, purification and characterization. Colloids and Surfaces B: Biointerfaces, 2010, 79, 246-253.

(13) Ma, X., Li, H., Song, X., Surface and biological activity of sophorolipid molecules produced by Wickerhamiella domercqiae var. sophorolipid CGMCC 1576. Journal of Colloid and Interface Science, 2012, 376, 165-172.

(14) Maddikeri, G., Gogate, P., Pandit, A., Improved synthesis of sophorolipids from waste cooking oil using fed batch approach in the presence of ultrasound. Chemical Engineering Journal, 2015, 263, 479-487

(15) Szpilman, A. M., Carreira, E. M., Probing the biology of natural products: molecular editing by diverted total synthesis. Angewandte Chemie (International ed. in English) 2010, 49, 9592-628.

(16) Bisht, K., Gross, R. and Kaplan, D., Enzyme-mediated regioselective acylations of sophorolipids. J. Org. Chem., 1999, 63, 780-789.

(17) ed. Hill, K., ed. von Rybinski, W., and ed. Stoll, G., Alkyl Polyglucosides: Technology, Properties, and Applications., Henkel, Düsseldorf, Germany, 2008.

(18) Zhang, L., Somasundaran, P., Singh, S. K., Felse, A. P. and Gross, R.A., Synthesis and interfacial properties of sophorolipid derivatives. Colloids and Surfaces A: Physicochem.Eng. Aspects, 2004, 240, 75-82. 
(19) Shin, J. D., Lee, J., Kim, Y. B., Han, I., Kim, E.; Production and characterization of methyl ester sophorolipids with 22-carbon-fatty acids., Bioresource Technology, 2010, 101, 3170-3174.

(20) Koh, A., Linhardt, R., Gross, R., Effect of sophorolipid n-alkyl ester chain length on its interfacial properties at the almond oil-water interface. Langmuir, http://dx.doi.org/10.1021/acs.langmuir.6b01008.

(21) Goebel, A., Lunkenheimer, K., Interfacial tension of the Water/n-Alkane Interface. Langmuir, 1997, 13, 369-372.

(22) Robust Summary for Crude Oil, American Petroleum Institute, http://www.petroleumhpv.org/petroleum-substances-andcategories/ /media/89F496D8432545ABB06D85D0BD5D99D1.ashx, (accessed August 2015)

(23) Peng, Y.; Totsingan, F.; Meier, M. A. R.; Steinmann, M.; Wurm, F.; Koh, A.; Gross, R. A. Sophorolipids: Expanding structural diversity by ring-opening cross-metathesis. Eur. J. Lipid Sci. Technol., 2015, 117, 735 217-228.

(24) Ward, A. F. H. and Tordai, L., Time-Dependence of Boundary Tensions of Solutions. I. The Role of Diffusion Time-Effects. J. Chem. Phys., 1946, 14, 453-461.

(25) Campanelli, J., Wang, X.; Dynamic Interfacial Tension of Surfactant Mixtures at LiquidLiquid Interfaces. Journal of Colloid and Interface Sciences, 1999, 213, 340-351.

(26) Shinoda, K., Yamaguchi, T., Hori, R., The surface tension and the critical micelle concentration in aqueous solution of $\beta$-D-Alkyl glucosides and their mixtures. Bulletin of the Chemical Society of Japan, 1960, 34, 237-241. 
(27) Simjoo, M., Rezaei, T., Andrianov, A., Zitha, P. L. J., Foam stability in the presence of oil: Effect of surfactant concentration and oil type. Colloids and Surfaces A: Physiochemical and Engineering Aspects, 2013, 483, 148-158.

(28) Cooper, D., Paddock, D., Production of a biosurfactant from Torulopsis bombicola. Applied and Envrionmental Microbiology, 1984, 47, 173-176.

(29) Ushikubo, F. Y., Cunha, R. L., Stability mechanisms of liquid water-in-oil emulsions. Food Hydrocolloids, 2014, 34, 145-153.

(30) Apenten, R., Zhu, Q., Interfacial parameters for selected Spans and Tweens at the hydrocarbon-water interface. Food Hydrocolloids, 1996, 10, 27-30.

(31) Santini, E., Liggieri, L., Sacca, L., Clausse, D., Ravera, F., Interfacial rheology of Span 80 adsorbed layers at paraffin oil-water interface and correlation with the corresponding emulsion properties. Colloids and Surfaces A: Physiochemical and Engineering Aspects, 2007, 309, 270-279.

(32) Niraula, B., King, T., Misran, M., Evaluation of rheology property of dodecyl maltoside, sucrose dodecanoate, Brij 35p and SDS stabilized O/W emulsion: effect of head group structure on rheology property and emulsion stability. Colloids and Surfaces A: Physiochemical and Engineering Aspects, 2004, 251, 59-74.

(33) Rusanov, A., Krotov, V., Nekrasov, A., Extremes of Some Foam Properties and Elasticity of Thin Foam Films near the Critical Micelle Concentration. Langmuir, 2004, 20, 1511-1516.

(34) Futamura, T., Kawaguchi, M., Characterization of paraffin oil emulsions stabilized by hydroxypropyl methylcellulose. Journal of Colloid and Interface Science, 2012, 367, 55-60. 
(35) Ashby, R., Solaiman, D., Foglia, T., Property control of sophorolipids: influence of fatty acid substrate and blending. Biotechnol. Lett., 2008, 30, 1093-1100.

(36) Pekdemir, T., Çopur, M., Urum, K., Emulsification of crude-oil systems using biosurfactants. Trans IChemE, Part B, Process Safety and Environmental Protection, 2005, 83, 38-46

(37) Bąk, A., Podgórska, W., Investigation of drop breakage and coalescence in the liquidliquid system with nonionic surfactants Tween 20 and Tween 80. Chemical Engineering Science, 2012, 74, 181-191.

(38) Kundu, P., Agrawal, A., Mateen, H., Mishra, I., Stability of oil-in-water macro-emulsion with anionic surfactant: Effect of electrolytes and temperature. Chemical Engineering Science, 2013, 102, 176-185.

(39) Davila, A. M., Marchal, R. and Vandecasteele, J. P., Kinetics and balance of fermentation free from product inhibition: sophorose lipid production by Candida bombicola. Appl. Microbiol. Biotechnol. 1992, 38, 6-11. 


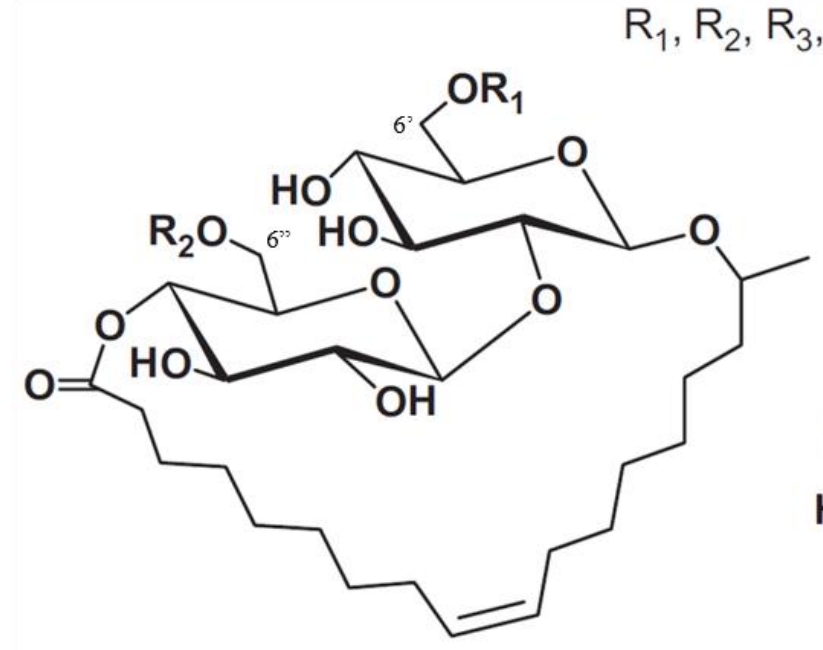

Lactonic Sophorolipid (LSL)

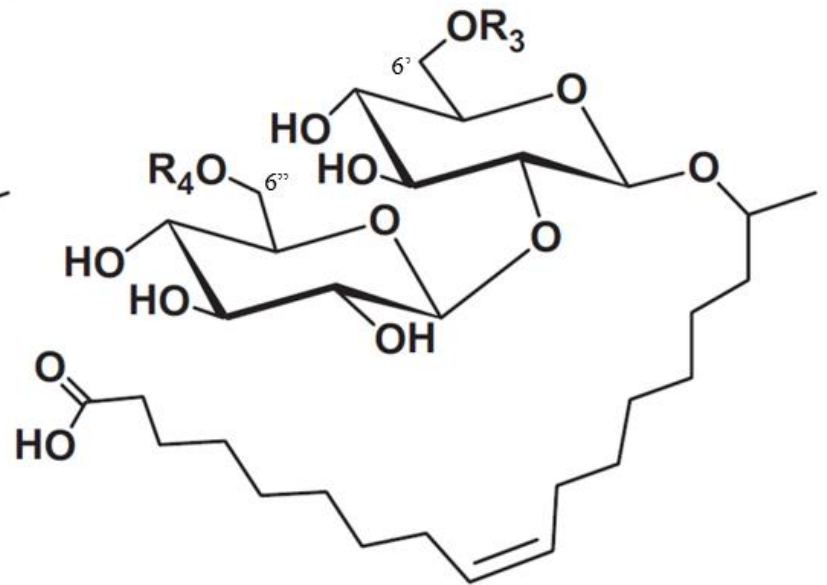

Acidic Sophorolipid (ASL)

Scheme 1. Structures of LSL and ASL indicating positions of possible acetylation [39].

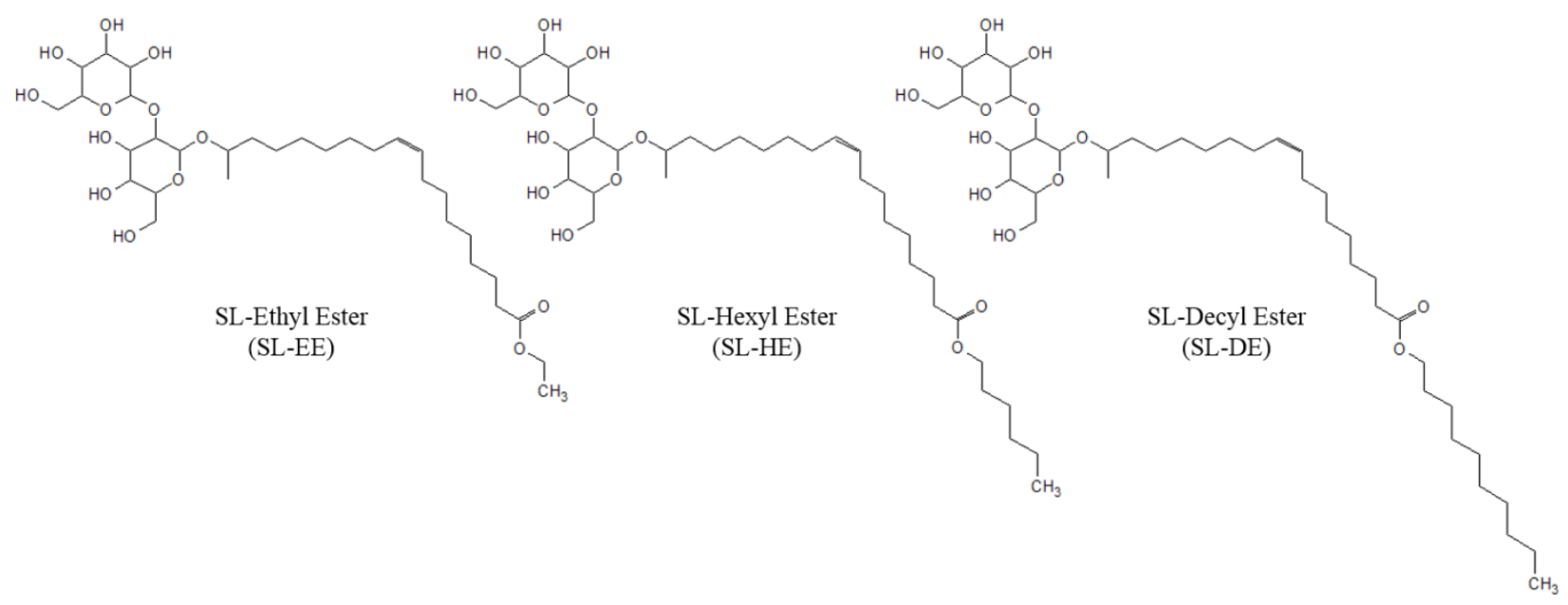

Scheme 2. Structures of SL-esters: SL-EE, SL-HE, and SL-DE. 


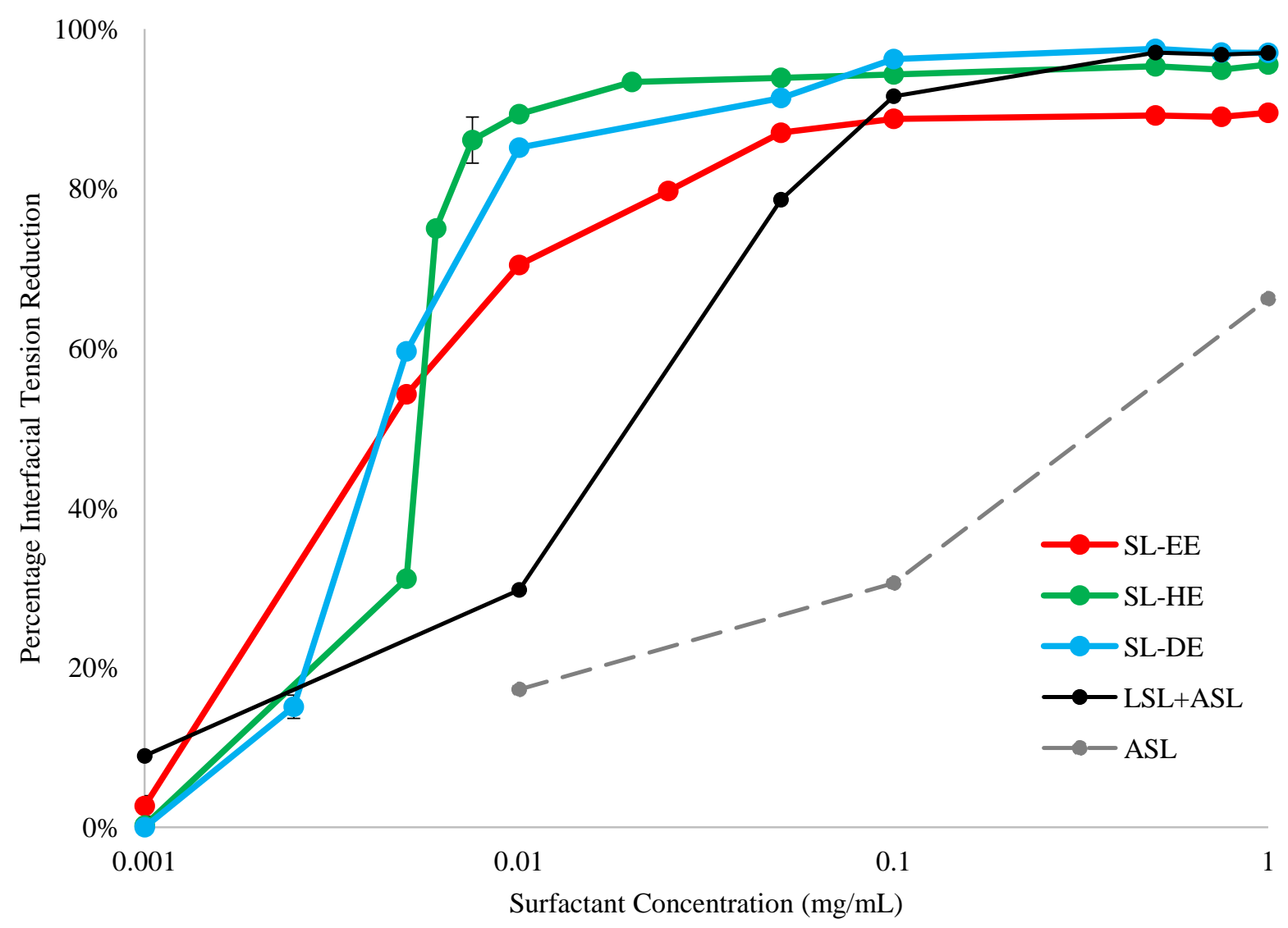

Figure 1. Equilibrium \%-IFT reduction for SL-EE, SL-HE, SL-DE, ASL, and LSL+ASL from 0.001 to $1 \mathrm{mg} / \mathrm{mL}$. Mean and standard deviation values are measured from at least three replicates.

\begin{tabular}{|l|c|c|c|c|c|}
\cline { 2 - 5 } \multicolumn{1}{c|}{} & \multicolumn{2}{c|}{$\begin{array}{c}\text { Critical Aggregation } \\
\text { Concentration }\end{array}$} & \multirow{2}{*}{$\begin{array}{c}\text { Max \% IFT } \\
\text { Reduction }\end{array}$} & $\begin{array}{c}\text { Min. IFT } \\
(\mathrm{mN} / \mathrm{m})\end{array}$ & $\begin{array}{c}\text { IFT } \\
\text { Reduction } \\
(\mathrm{mN} / \mathrm{m})\end{array}$ \\
\cline { 2 - 3 } \multicolumn{1}{c|}{$(\mathrm{mg} / \mathrm{mL})$} & $(\mathrm{mol} / \mathrm{L})$ & & & \\
\hline SL-Ethyl Ester & 0.020 & $3.0 \mathrm{E}-05$ & $89.2 \% \pm 0.3 \%$ & $6.0 \pm 0.2$ & 49.5 \\
\hline SL-Hexyl Ester & $\mathbf{0 . 0 0 8}$ & $\mathbf{1 . 1 E}-\mathbf{0 5}$ & $95.2 \% \pm 0.3 \%$ & $2.7 \pm 0.2$ & 52.8 \\
\hline SL-Decyl Ester & 0.011 & $1.4 \mathrm{E}-05$ & $\mathbf{9 7 . 2 \%} \pm \mathbf{0 . 3 \%}$ & $\mathbf{1 . 6} \pm \mathbf{0 . 1}$ & $\mathbf{5 4}$ \\
\hline LSL+ASL & 0.099 & & $96.9 \% \pm 0.1 \%$ & $1.7 \pm 0.1$ & 53.8 \\
\hline ASL & 1.2 & $2.0 \mathrm{E}-03$ & $79.9 \% \pm 1.7 \%$ & $11.1 \pm 0.9$ & 44.4 \\
\hline
\end{tabular}

Table 1. Critical aggregation concentration and max \%-IFT reduction for SL-esters, L+A, and ASL. 

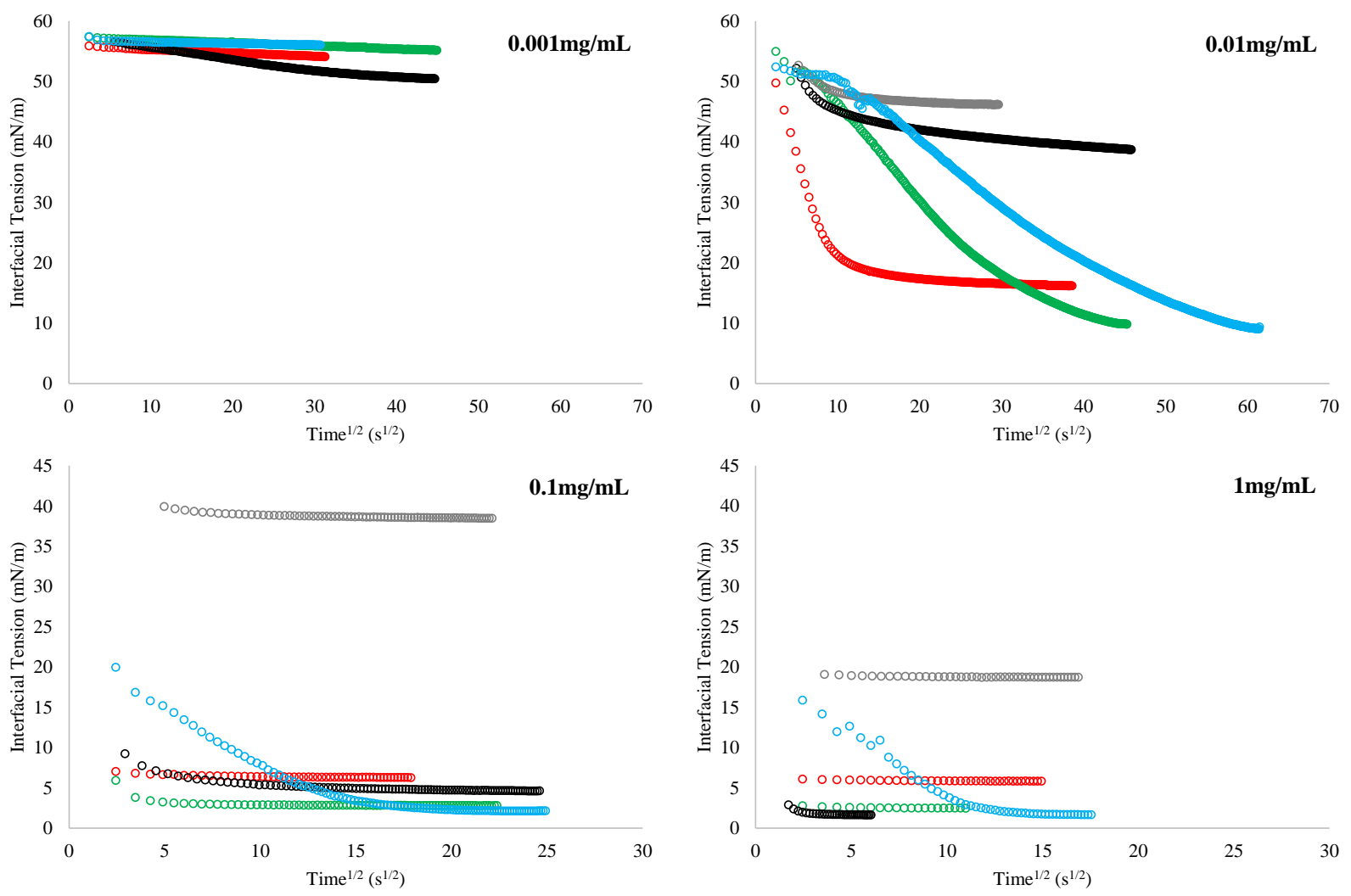

$\longrightarrow$ SL-EE $\longrightarrow$ SL-HE $\longrightarrow$ SL-DE $\longrightarrow$ L+A -- ASL

Figure 2. Dynamic IFT for $0.001,0.01,0.1$, and $1 \mathrm{mg} / \mathrm{mL}$ of SL-esters, LSL+ASL, and ASL at the paraffin oil/water interface.
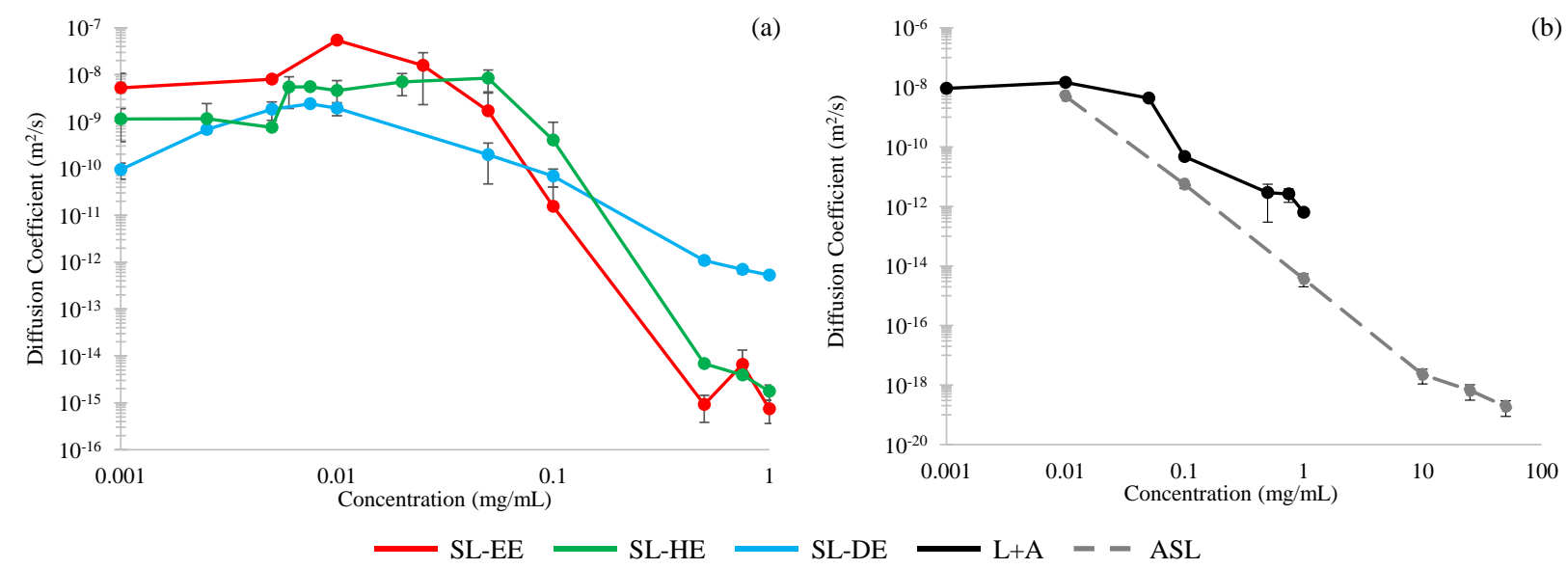

Figure 3. Diffusion coefficients for SL-esters, LSL+ASL, and ASL. Note that the $\mathrm{X}$-axis of the two plots are scaled differently. Mean and standard deviation values are measured from at least three replicates. 

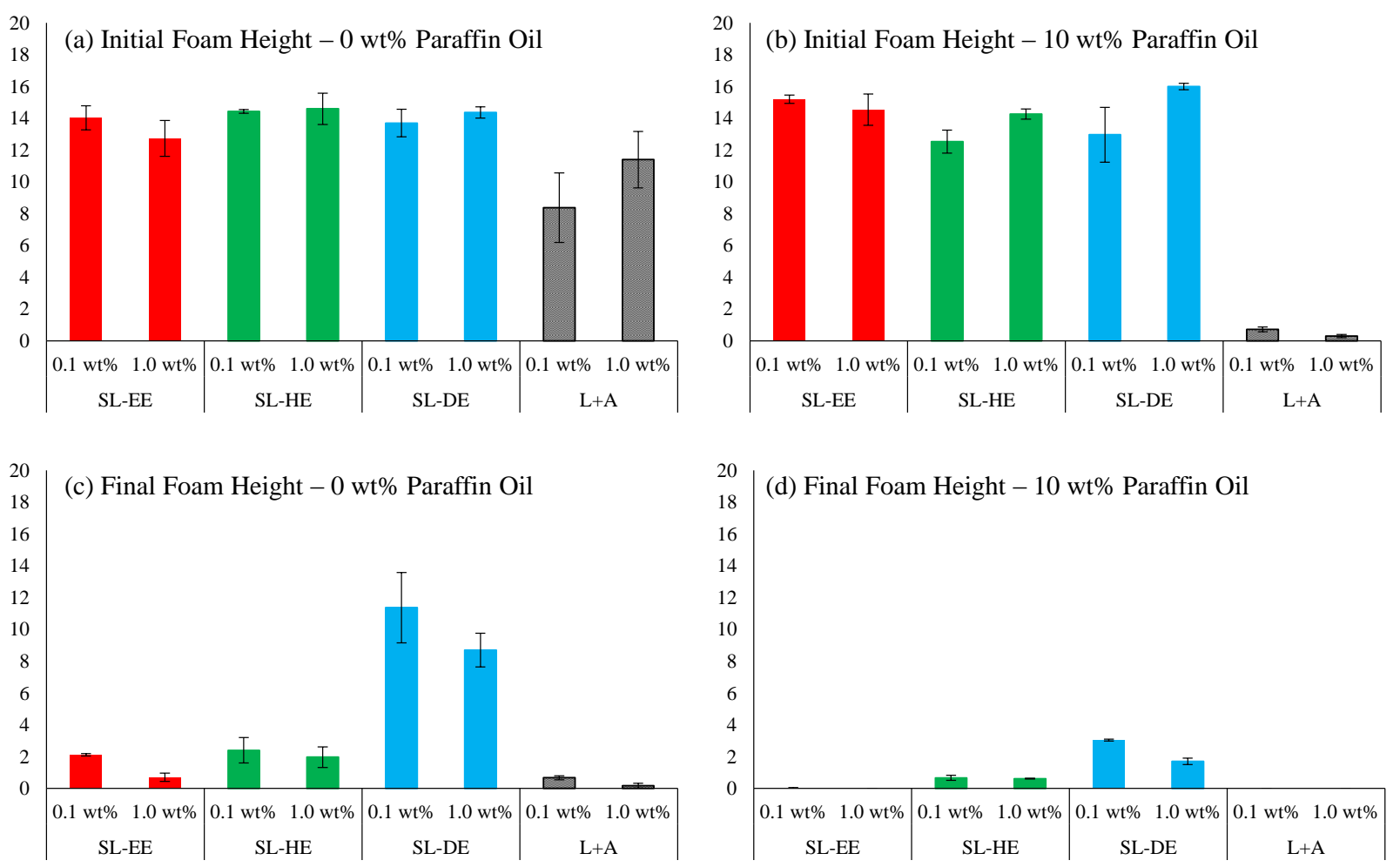

Figure 4. Short- and long-term foaming behavior at 0.1 and $1.0 \mathrm{wt} \% \mathrm{SL}$ in the presence of no oil or $10 \mathrm{wt} \%$ paraffin oil. Mean and standard deviation values are measured from at least three replicates. 

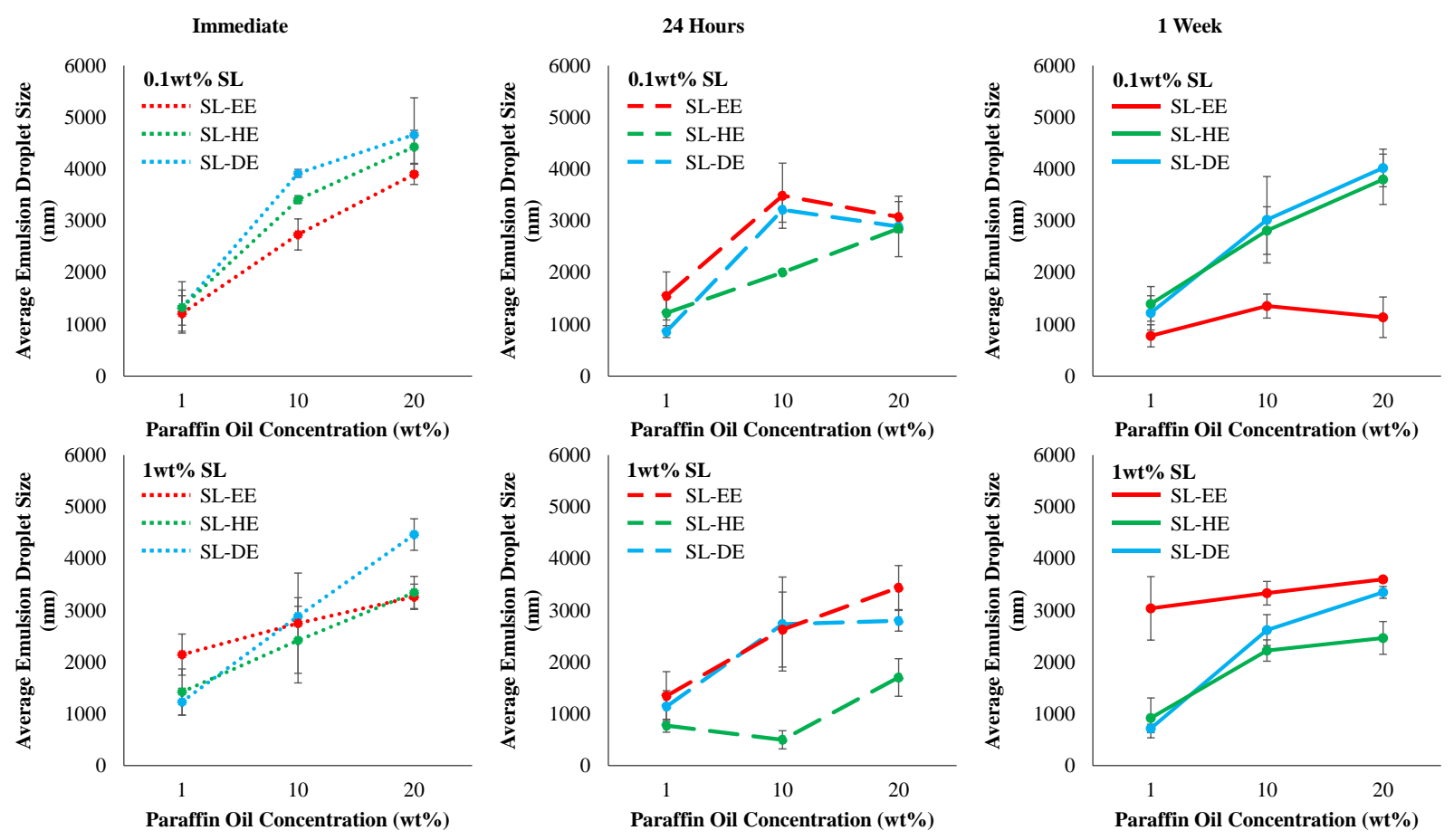

Figure 5. Average emulsion droplet sizes of SL-esters immediately after emulsification and after $24 \mathrm{~h}$ or 1 week of aging at $25^{\circ} \mathrm{C}$. Mean and standard deviation values are measured from at least three replicates.
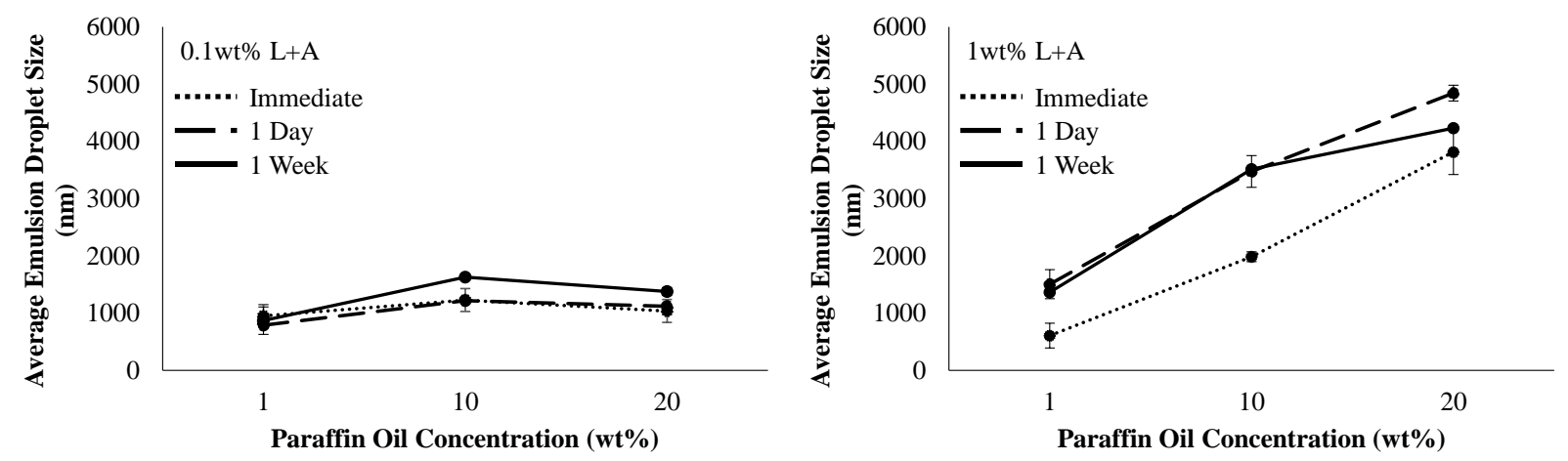

Figure 6. Average emulsion droplet sizes for L+A emulsions of paraffin oil. Mean and standard deviation values are measured from at least three replicates. 

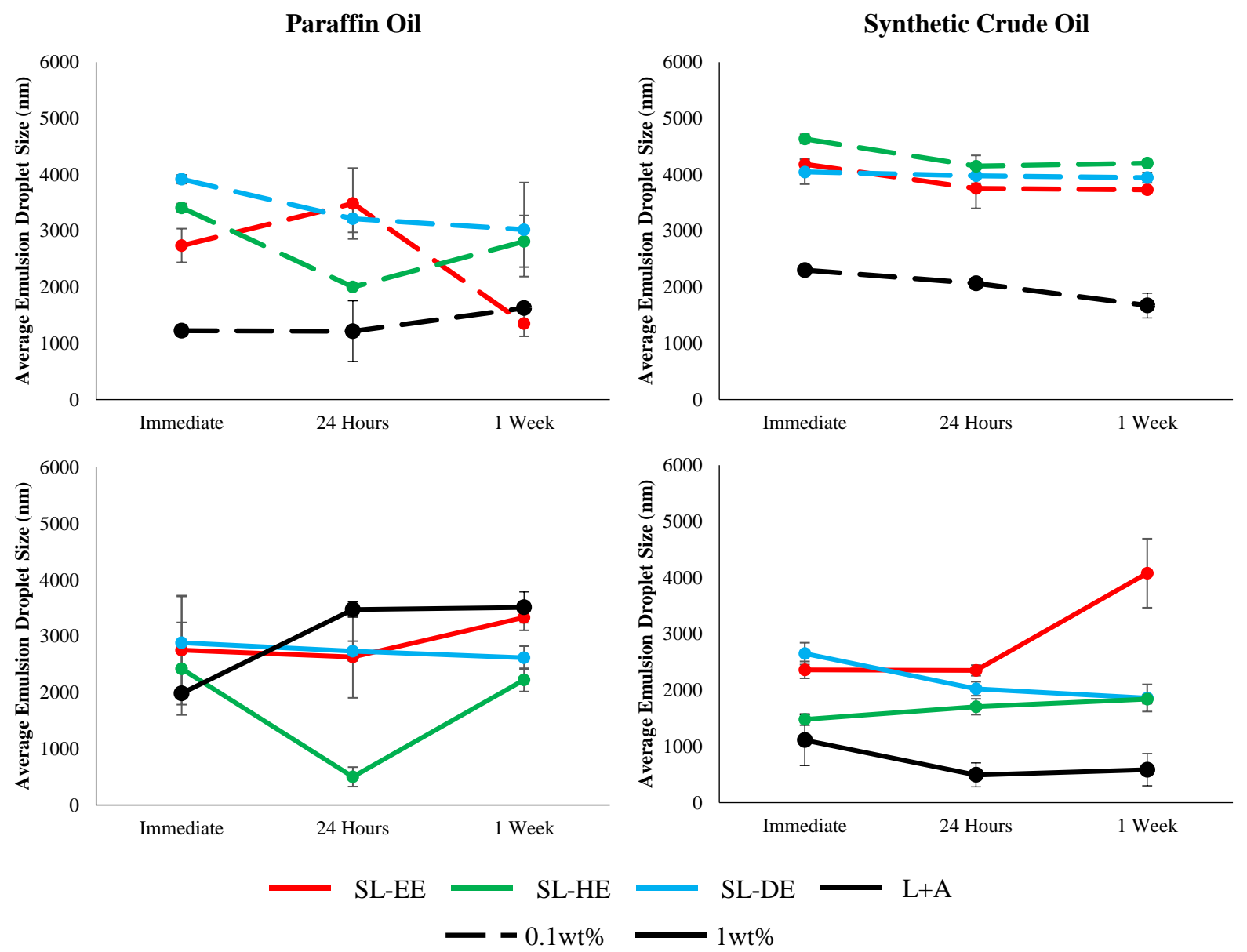

Figure 7. Emulsions of $10 \mathrm{wt} \%$ paraffin or synthetic crude oil with 0.1 or $1 \mathrm{wt} \%$ SL. Mean and standard deviation values are measured from at least three replicates. 


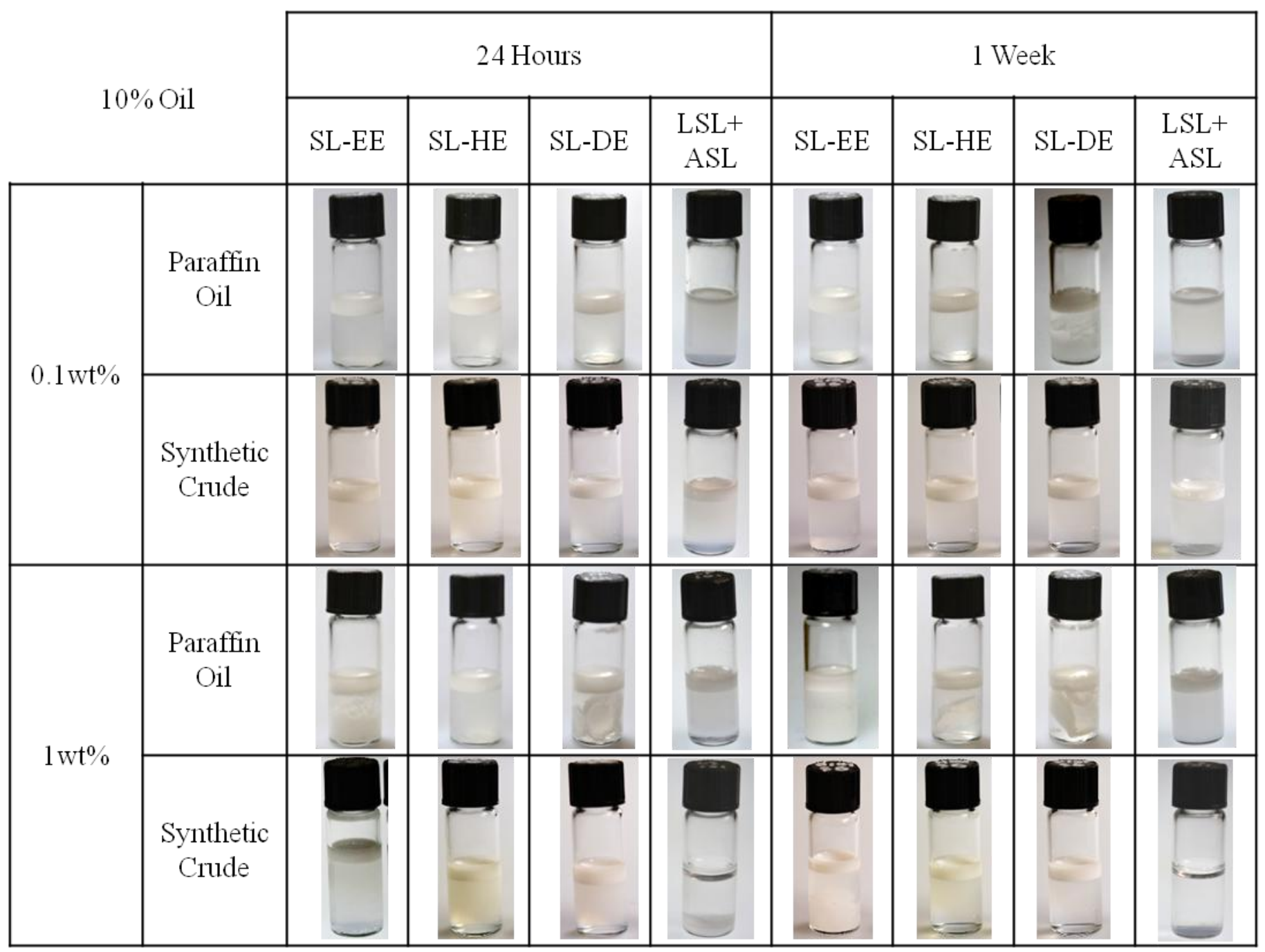

Table 2. Physical appearance of 10wt\% paraffin and synthetic crude oil emulsions stabilized by SLs after $24 \mathrm{~h}$ and 1 week of aging. 